\title{
Confucius and Immanuel Kant: The Problem of Virtue and Morality
}

\author{
Nazgul Zhanisovna Kudaibergenova ${ }^{1}$, Saniya Edilbay ${ }^{1}$, Gulzhan Kanaevna Abdigalieva ${ }^{1}$ \& Zhandos \\ Zhumalbekovich Kumganbayev $^{1}$ \\ ${ }^{1}$ Al-Farabi Kazakh National University, Kazakhstan \\ Correspondence: Nazgul Zhanisovna Kudaibergenova, Al-Farabi Kazakh National University, 71 Al-Farabi Ave., \\ Almaty, 050040, Kazakhstan. E-mail: nazgul_1507@mail.ru
}

\author{
Received: May 4, 2015 Accepted: May 13, 2015 Online Published: July 30, 2015 \\ doi:10.5539/ass.v11n19p211 URL: http://dx.doi.org/10.5539/ass.v11n19p211
}

\begin{abstract}
The article presents the results of a comparative analysis of the basic principles of Confucius and Immanuel Kant ethics, and made an attempt to make a reconstruction of the moral ideal in the context of comparative philosophy of the East - West. Particular attention was paid to the following objectives: - to perform a comparative analysis of the Confucius teachings and Kant's philosophy to recreate the spiritual significance of Confucian and Kantian philosophy in understanding the issues of virtue, moral and spiritual development of man - based on existing research in the field of comparative studies, Confucianism and Kantian ethics to analyze the ontological, anthropological, moral content of these teachings. To reveal the essence of humanistic social and ethical teachings of Confucius and the philosophy of Kant. The philosophical teaching of Confucius had a profound impact on the development of ethical thought in China. In Western philosophical space Immanuel Kant is a significant figure, and developed by him the doctrine of moral categorical imperative and an autonomous morality is the basis of almost all further attempts to build ethical models in the West.
\end{abstract}

Keywords: Confucius, I. Kant, ethics, virtue, comparative studies, Lun Yu, categorical imperative

\section{Introduction}

\subsection{Introduction to the Problem}

In recent years, the problem of finding the global values of Confucian tradition, as well as its interaction with the West-European philosophy has become the central issue of many philosophical studies. The representatives of the so-called "New Confucianism" who since the late 20s of the last century have been widely discussed issues of democracy, openness and cultural and religious tolerance, initiated this process.

\subsection{Actuality of the Problem}

The concept of "humanism", in other words "humanity", focuses on a man-individual, person, or group of people or family considers as a certain form of existence. From here originates the basic assertion of humanism, that man, or rather, man's life has some form of unconditional (congenital) human value. The concept of unconditional (congenital) human value, the moral principles and moral values are the basis of fundamental moral principles in many humanistic systems.

Two great thinkers in the history of philosophy - Kant and Confucius - shared commitment to morality, which they represented not only as a final duty of human existence, but also as the highest expression of humanity (humanity). Both thinkers have tried to guide humanity on the path of formation of moral principles and values. Morality is not always the result of civilization, as it was noted by Rousseau (Rousseau, 1998). Philosophers from almost every era lamented the deplorable situation of morality in their era and were convinced that they were witnesses to the moral decline as a result of many years of destruction and neglect of moral value system. Kant notes that (To a high degree, we are, through art and science, cultured. We are civilized - perhaps too much for you own good - in all sorts of social grace and decorum. But to consider ourselves as having reached morality - for that, much is lacking) (Kant, 1988). Confucius also noting the decline of moral standards of his era, recalled the old days, when the virtuous rulers, such as emperor of the Zhou Dynasty and mythical emperors Zfj and Shun were the moral inspiration for the people.

The teachings of Confucius largely determined the basic parameters for the development of Chinese philosophy. The philosophical teaching of Confucius had a most profound impact on the development of ethical thought in 
China. Confucian teachings originally evolved as an ethical and political doctrine, focused primarily on morality and ethics in politics and education, so that created a unique socio-cultural genotype underlying the reproduction and the functioning of the Chinese society. In Western philosophical thought on the other hand, Immanuel Kant's doctrine of morality, autonomy of the morality has become a kind of the basis of follow ethical philosophies of the West. Comparative analysis of the ethical teachings of the philosophers from the standpoint of the philosophy comparative studies is possible, based on the value approach to the creation of the two thinkers.

\section{Method}

In the article a comparative analysis of the ethical concept of Confucius and Kant was made. To perform this task, we use in preference the dialectical method with its basic categories and principles that have been created by G. F. F. Hegel and developed by K. Marx, as well as well-known representatives of the dialectical logic, such as J. M. Abdildin, G. S. Batishchev, E. V. Ilyenkov, L. K. Naumenko, K. Jaspers and others. And also, for the disclosure of the subject such methods are used: ascent from the abstract to the concrete, historical and logical generalization, systematization.

The article also uses the following methods of comparative studies: comparative historical method, analogies method, synthetic method. In the analysis of the historical and philosophical text of ancient Chinese philosophy textual and evaluative techniques were used.

Undoubted role in uncovering the topic of this article played the works which carried matching of eastern and western worldview, Eastern and Western philosophy, as well as analyzed the features of the basic categories of the traditional ancient Chinese philosophy. These are the works of M. T. Stepanyants, T. P. Grigorieva, A. I. Kobzev, Froese K., Tu Wei-ming, Moe Tszunsan.

\section{Results}

The comparative method and Hermeneutics of Confucian texts and the ethical principles of Kant allowed revealing and justifying the following: 1) The principle of "respect for the moral law" is the basis of Confucian and Kantian ethics. 2) In the ethical concepts of Confucius and Kant we can see certain things in common. According to Kant, the debt is something other than moral purity of motive and firmness of moral convictions. Through debt moral value alleges that inherent in each man as a rational and moral being. Confucius category "jen" is human beginning in man, which is also his duty. We cannot say who is a person at the same time don't answer on the question of what are the signs of his moral. 3) According to the ethical concepts of Confucius and Kant, man is called to be encouraged the mind to moral behavior that is expressed in veneration of the moral law. The meaning of life is in the connection of virtue and happiness. Only such a duty, which contributes to the happiness of man and mankind, is an ethical value.

\section{Discussion}

\subsection{Wise Confucius Ethics}

Philosophy arises at a certain stage of historical development of human culture. Karl Jaspers called it "axial time", and refers "to the spiritual process, which was between 800 and 200 years. BC "(Jaspers, 1991).

VI - IV centuries BC was in China "golden centuries of philosophy", as all the major philosophical trends and ethical-political schools appeared there during this period. This intelligent surge defined in the millennium ahead the development of the spiritual life of Chinese society.

According to traditional Chinese chronicles a period of Chun Qiu (770 - 476 BC.) - Zhang Guo (475 - 221 BC.). Chinese philosophy teachings took shape in the form of two major schools - Taoism ("Jia Dao") and Confucianism ("Ms. Jia"). Their founders were thinkers Lao Tzu and Confucius. But philosophy did not appear out of nowhere. It is preceded by a long period of formation of the premises and conditions of its appearance.

A prerequisite for the development of philosophy in China has been long-term accumulation and assimilation of knowledge about the laws of the world device. At this stage of development the ancient Chinese man sees himself as part of nature, not separate from it his consciousness. But it was a natural stage of development, when "the emergence of ideas" connected directly with the physical activity of people and language. The researcher of ancient Chinese philosophy, A. E. Lukyanov, noted that "in the final stages of the tribal organization, they formed gnoseo-ontological structure of the pre-philosophic mind, when body-spiritual categories of the opposition of top and bottom precede active cognitive work of thinking in all aspects of the emerging philosophy - philosophical anthropology, sociology, cosmology and epistemology" (Perelomov, 1993).

"Golden Age" of philosophy in China has been directly linked with the intellectual activities of many members of a particular social category - "shi". It is "shi" inheriting and developing the traditional mind had to move with 
the method of dialectical views on the nature of people when they are engaged in the creation of different models of social organization. The question arises, what are the "shi".

In the VIII-VI centuries BC the term "shi" refers to the descendants of the very low level of aristocratic patronymy (tsung-tzu). It used to be warriors, and not noble officials. The VI-III centuries BC the scope of their activities gradually expanded, being intelligent and competent people, many of them are engaged in an active intellectual activities.

Philosophers, culture experts, psychologists, theologians, sociologists, anthropologists, and other representatives of the various branches of science XX century reflect on the problem: What is man, and how a person should live. To date, the problem of man is very relevant in all areas of science, as a person as a result of their active work gave their habitat on the brink of a catastrophic failure.

The study of human nature and destiny began in Europe as well as in the East, long before our era.

Any philosophical doctrine of man always comes from a specific doctrine of the world as a whole. Every anthropology assumes ontology (categorically unacceptable to the scientific discourse). Of course, in some philosophical system the doctrine of the world can take place more or less, and may even have an implicit nature, i.e. only implied. It can be developed by this philosophy as a system, as it can be borrowed from other philosophical system; but it is always be. After all, people somehow determined through the world, through its relationship to the world. In philosophy, S.L. Rubinstein noted "the question is not only about the man in the relationship with the world, but also of the world in relation to man as an objective attitude" (Rubenstein, 1997). At the same time, man is a social creature, cultural. Consequently, there is also an objective relation of man to society and society to the man. For the teachings of Confucius and the Confucian philosophy the problem of man is more important than for the Taoist philosophy. This is due to the primarily feature of this philosophical system. In Confucian philosophy ontological issues are not specifically taken up and do not find their solutions. All of the major problems of Confucian teachings focused on man and society, so that it can be very generally defined as a social philosophy. But in this article we will try to show that this is a very specific social philosophy.

The founder of the Confucian teachings Confucius argued that the deep antiquity was perfect in relation to organization of society and human behavior in it. This epic times were of Yao, Shun, Yu, and when viewed in historical chronology, this is the era of Zhou (Western Zhou period). An important objective Confucius believed to convey to his contemporaries ideas and ideals of the period. He said: "I continue - do not create; I believe in the antiquity and love her wholeheartedly "(Luyuy).

In the ancient Chinese philosophy important categories were "sky" ("Tian"), "earth" ("di"), "man" ("Ren"), the path ("Tao"), morality or virtue ("de"), fate ("m"), the "will of heaven" or "heavenly predestination" ("Tian minutes"). Confucius took these universals of ancient philosophy. An important ontological category of Confucian philosophy is a "sin" - "nature" (meaning human nature or human nature).

The philosophy of Confucius saved personal assessment of the subject-category "tian" ("Sky"), however, Confucius gives heaven such a feature as justice, moreover, absolute justice. Confucius did not doubt that the sky comes true. Sky expresses their will to everyone, and it will certainly valid. "Life and death - says Confucius dependent on the dictates of Heaven, gentility and wealth are sent from heaven" (Lun Yu).

Thus, the category of "Tian" in Confucian philosophy has a religious, political, ideological and ethical function. Confucius assigned the sky as a divine principle place above the spirits and souls of the dead ancestors. Toward the traditional beliefs of his time Confucius was also a conservative. There are some several passages in the Lun Yu recording his views about Heaven (tian 天):

(Wang-sun Chia inquired: (What is the meaning of the saying. It is better to pay court to the god of the hearth than to the god of the hall? (Not so, said the Master). He who sins against Heaven has no place left where he may pray). The Master said: (I make no complaint against Heaven not blame men, for though my studies are lowly my mind soars aloft. And what which knows me, is it not Heaven). When Yen Yuan (the favorite disciple of Confucius) died, the Master exclaimed: (Alas! Heaven has bereft me! Heaven has bereft me!).

The passages show that Heaven for Confucius mean a purposeful Supreme Being or (ruling Heaven) (Fung, 1973).

Another important category is the Confucian "destiny" ("min"), often in conjunction with the "sky", that is the category of "the will of heaven" or "heavenly decrees" ("Tian min"). The researchers note that "min" is not very much in common with the Western understanding of destiny. In the West, the fate is generally understood as a blind predestination and absolute lack of freedom. Name? Grigorieva noted that "it is not a blind force, not a rock, and the higher destiny which man is to fulfill, if he wants to follow the right path that leads to liberation 
from every kind of dependence" (Grigorieva, 1994). So man in the teachings of Confucius has a certain freedom in relation to the fate he could follow it, and may take a different path.

Confucian philosophy inherited from the ancient philosophy as a category "the way" ("Tao") and "virtue ethics" ("de"), making them the main categories of his philosophical doctrine. "Te" in the Confucian texts also translated as "grace" and how "the power of the spirit." On the category of "dao" Confucius said: "Whoever hears about the way in the morning, he can die in peace at night."

Another important ontological category of Confucian philosophy is the "nature" ("Sin"). This category of Confucians attached great importance, although it is rarementioned in Lunyu. But the essence of man is not determined by Confucian philosophy in its relationship with nature, and in opposition to nature. The essence of a person is considered to imply a supernatural, namely socio-cultural. Man by Confucius, like other philosophers of ancient China, is considered first and foremost as a social creature, and society is the basic semantic context in which the problem of human purpose is discussed. In this regard it should be noted the specificity of understanding of Confucius and his followers of what is society and social. Society, according to them, is the unity of society and the state, headed by the ruler (the "son of heaven"), but the state and governance, and human society is not yet understood politically, but purely social. But the very social in Confucian philosophy is interpreted primarily ethically. Thus, Confucius (and in Confucianism) ethical principle prevails over all others. According to Hegel, "the teachings of Confucius ... are a moral philosophy. But say that the philosophy of Confucius is only ethical, would be a mistake, in my opinion, the ethics of Confucius - is not ethics in the narrow sense, but not in the sense of Spinoza's Ethics. The philosophy of Confucius and the Confucian doctrine, in my opinion, can be defined as ethical and social teaching, where questions of morality and virtue go hand in hand with social problems "(Hegel GF, 1932). From this it follows that the problem of man, the problem of human morality, virtue, perfection, purpose is comprehended in the ethical and social context. In view of these points, we can say that people in Confucian philosophy is understood primarily as an ethical subject.

The next question that we consider - is the ratio of human nature and human essence. By Confucius, according to many researchers, the nature of man is understood as neutral with respect to good and evil. This shall be judged according to the following saying of Confucius: "The nature of each other brings them together, habit separates from each other." From this statement it follows that the nature of all people is the same, and a penchant for good or evil, and there is produced in the process of socialization. Thus, the neutrality of the human nature of good and evil to Confucius is the starting point of the education of the person in the right direction that is, grafting him virtues.

Since the philosophy of Confucius is the ethical-social, the essence of man is a system of elements comprising it, the core of which are the "five permanent members" ("u Chan") They are "humanity, kindness and humanity" ("jen", "due justice" ("i"), "ethical and ritual propriety" ("li"), the "wisdom, reason" ("ji"), "trustworthiness, trust " ("sin").

The most basic of the five constancies Confucius believed "humanity" ("jen"). The most simple and common definition of humanity is contained in the answer to the question of Confucius pupil Fan Chih. Fan Chi asked what humanity is. The teacher replied, "This is love for people." That value, which Confucius gave humanity is evident from his next words: "Humanity is more important to people than water and fire." Therefore, according to Confucius, aspiration for humanity is beneficial in itself: "Aspiration to relieve humanity from all evil." Humanity, according to Confucius, gives a man a special ability to correct, objective attitude to the people: "Only one who is human, and knows how to love people and to feel an aversion to them." Humanity, according to the teachings of Confucius, - it does not do to others what you do not wish for yourself. This formula is repeated many times in the Lun Yu.

Another important category among five constancies is a "ritual propriety" ("Li"). "Li" - this is not a formalized ceremony, but rather, a manifestation of the rules of conduct, etiquette inherited from antiquity. The value of the ritual is described in the "Book of rites" ("Li Ji"): "The ritual for the people - is like leaven for the wine." That is, the ritual is an integral part of everyday life. According to Confucius, harmony must take $\mathrm{n}$ a specifically human form through the use of ritualized patterns and social relationships (li). $\mathrm{Li}$ is one of the most salient markers of our humanity: (Achieving harmony is the most valuable function of observing ritual propriety. But when things are not going well, to realize harmony just for its own sake without regulating the situation through observing ritual propriety will not work) (Froese, 2013).

For Confucius, as mentioned above, from five constancies the most important is "humanity" ("jen"). Confucius said: "What rituals as if the person does not show humanity?) Humanity, according to Confucius, is also based on other ethical virtues that are not included in the "five constancies" ("u Chan"). 
In Confucian philosophy there are two types of people, or two models defined by ethical criteria. They are the "noble man" ("Jun Zi") and the "little man" ("xiao jen"). "Jun Zi", "noble man" is endowed with only positive ethical characteristics and is the owner of all five qualities "u Chan."

Confucianism in matters of ethical issues is a major structural and organizing intellectual and spiritual factor in the development of Chinese culture. So, H. Roetz, who devoted the problem of Confucian morality the monograph "Chinese axial age ethics," writes: "Morality is seen as the main theme of Chinese Philosophy, especially Confucianism) (Roetz, 1992). Kobzev also notes "a specific etizirovannost of traditional Chinese philosophy" (Kobzev, 1988).

Under the etizirovannost the absolute predominance of the ethical issues in Chinese philosophy is understood. The scope for the Chinese ethical philosophy has always been not only a priority, but also extremely broad. For comparison, in Europe, in particular the allocation of ethics philosophical disciplines with a special terminological designation and its own subject of study in the IV century BC were realized by Aristotle. In addition, since the time of the Stoic ethics was considered one of the three main parts of philosophy, and in the post-Kantian era was recognized as a special science - a field non-empirical due.

In Europe, since ancient times there is a philosophical tendency towards the universalization of ethics, but it never dominated in European philosophy. In Chinese philosophy, which never opposed religion itself, but successfully assimilated it, there was no specification of ethics, as well as the fundamental differentiation in the latest theoretical and practical, and things ought to be, so the moral sphere has always been considered an extremely broad and ontologically conditioned. "The main types of knowledge differ in their moral significance and the fundamental parameters of being interpreted in ethical categories" (Kobzev, 1988).

It is this specific feature of traditional Chinese ethics allows us to speak, as some researchers and interpreters of Confucianism consider on the development of their unique theory - the "moral metaphysics" - which, in turn, actualize the research related to the practical philosophy of Kant. Due to the Kantian formulation of the problem of correlation of morality and religion, the modern Chinese philosopher Mou Tszunsan notes feature of Confucianism as follows: "The Confucian morality-te is not closed in a limited sphere with the religion is not two opposing areas as it in the West. Morale there have unlimited penetration. Moral actions have borders, but the reality on which they are based and by which are such limitless" (Moe, 1968). Another Chinese philosopher Tu Wei Ming writes: "Confucian ethics with the need extends to religion" (Ming, 1979).

The European concept of ethics has no direct counterpart in the Chinese culture. Analysis of extracts from Lun Yu can be used for the reconstruction of the ethical categories. We can say that Confucian philosophy is a kind of means to improve "humanity" ("jen") as a kind of deep ontological level, "the core" of the human being. In general, the teaching of Confucius it is fair to be defined as "the art of achieving humanity" [Lun Yu, VI, 30]. Since the latter is not given to everyone, although Confucius and believed that, in principle, you can train all without making distinctions [Lunyu, XV, 39], in the selection of his students, he exhibited the following limitations: "He who has no aspirations I do not reveal anything. Someone who is not distressed not trained. Do not answer to those who cannot, for one corner of the square to judge the remaining three " [Lun Yu, VII, 8].

Thus, "humanity" ("Jen") - is quality, which should have a modern man. But what it is possible to define the concept of "humanity"? In Confucianism "humanity" - "Jen" - is a state when a person gives himself fully the way, is filled with the ability to perfect loyalty and trust, respect for human dignity. "Jen" - is the power, virtue, the man radiated. "According to Confucius, it humanizes man is not nothing like the ability to understand their lives, judging himself to improve in all - the ability given to man by nature, and yet we have implemented through the incessant and arduous effort. In it converge and lead to equilibrium, causing each other's natural and cultivated, knowledge and action" (Institute of Philosophy and Law, 2007).

\section{2 "The Ethics of Duty" of Immanuel Kant}

Ethics has become the central object of philosophical study by Kant. One of the three major works of Kant's critical period, "Critique of Practical Reason", devoted to the study and justification of morality.

(Kant's moral theory is typically considered to be a prime example of an ethics of duty, sometimes categorized as deontological ethics. After all, what we are morally required to do, according to Kant, can be derived only from a non-empirical standard of rationality, namely the Categorical Imperative. It provides the sole principle for moral evaluation) (Betzler, 2008). Ethics Kant's is peculiar to doctrine of the independence and autonomy of morality. The predecessors of Kant and his contemporaries believed that the foundation of ethics is in religion. Kant does not agree with this concept and proclaimed morality independent of religion and moral law is not deducible from the religious commandments. In "Base of Metaphysics of Morals" Kant tries to justify "the supreme principle of 
morality." He explains the principle of morality in a totally rational, not empirical term - in order to avoid a situation where the moral actions will depend on the circumstances of human feelings, emotions, and other conditions.

Kant argues that morality does not depend on the nature of man. Moreover, the dominant ideological and theoretical dominant of Kantian conceptualization of human acts a pronounced antinatural orientation in the interpretation of the nature and essence of man as a special order in their ontological and axiological coordinates. "Kant decisively rejected peculiar to his era naturalistic approach to philosophical and anthropological issues and unfolded criticism dominated model in the interpretation of the essential characteristics of man and his way of life" (Chukhina, 1989). Theoretically significant point in this regard is that Kant was able to finally abolish the naturalistic paradigm, built on the antithesis of "natural - reasonable", replacing it with a new paradigm, based on the sharp contrast of natural (natural) moral (unnatural), put forward at the same time fundamental for its thesis about the fundamental concepts of unnatural true human in man. Revealing the essence of the problem of anthropogenesis by Kant, E. Y. Solovyov said: "If in his solicitude for man Kant's ruthless nature, in their human forms it is unnatural. Nature wants from him what not found in nature, namely morality and, moreover, autonomous morality "(Solovyov, 1978). From this we can conclude that the main product anthropogenes for Kant is the moral.

The same can be found in the philosophy of Confucius. According to the teachings of Confucius, the development of a true "humanity" ("jen") is the duty of every "perfect personality" ("Jun Zi"). "Jen" is the central category of Confucian anthropology in general and Confucian ethics in particular that in some way can be interpreted in the Kantian spirit, such as the Confucian version of the "categorical imperative." No wonder that $\mathrm{H}$ Roetz translats Chinese "jen" as "internal morality) ((die innere Moralitaet))

The problem of "human nature" ("Zhen Xing") is one of the fundamental problems in traditional Chinese philosophical system. The category of "sin" here means the natural qualities of individual things, especially man behind this worldviews, according to which a person thinks one of the "ten thousand [births] things ("wan $\mathrm{y}^{\prime \prime}$ ), forming the world. In Lun Yu the term "sin" is found only twice. In the first case, it is just starting a fact of Confucius reluctance to talk about "human nature": "The judgments of the teachers about wen culture can be heard. Teacher's judgments of human nature and the Tao-path cannot be heard" (Lun Yu, V, 13). But there is a fundamental and important statement of Confucius: "By nature, people are close to each other, and out of habit are far apart" (Lun Yu, XVII, 2).

From Confucius originated the idea that the natural determination can be overcome by ethics. Teacher often spoke of human "self-overcoming" ("Zi ke"), development of moral qualities through "culture" ("wen"), a true "humanity, and humanity" ("jen"), "morality" ("de") and etc, in order to destroy a barbarian and an egoist. The climax of the Confucian anthropology is a "perfect person" ("Jun Zi"); at the base of the pyramid is the Confucian anthropological "little man" ("xiao jen"). Thus in Confucianism "xiao jen" was considered not so much as an immoral person, but as a man without morals, a source "material" for the transformation and improvement in the direction of the perfect man, i.e., moral (in terms of the Kantian philosophy, the Confucian "little man" can be called a man of the phenomenal world, but "Junjie" - rated).

Thus Confucius soberly assessed the person as being a natural and often his sayings are full of bitter irony: "The wealth and nobility - that is what all men strive ..." (Lun Yu, IV, 5). That's all! I never met a man who, seeing his mistakes, he could condemn himself!" (Lun Yu, V, 27). Kant was also severe in the estimates of man as a creature emerging from the animal state and remaining in "laying in evil," the phenomenal world. In Kantian Humanities perverse human traits (pride, greed, selfishness, etc.) denotes a capacious notion of "primordial evil) ((das radikale Boese)), supposedly inherent in all human nature. On the other hand, Kant denied the independent substantiality of evil and in his concise sketch of initial instincts of human nature clearly manifests the dialectical mobility of boundaries between good and evil. L. A. Chukhina writes about this in her study of "Kant's position that man is by nature evil, means that both natural and natural being, he is an out of Moral" (Chukhina, 1989). As it is noted above, this is consistent with the views of Confucius.

Kant's ideas about morality in "basis metaphysics of morals" focused on three basic concepts: mind, will and duty. In the first place he puts the will. Will, especially the goodwill is necessary to comply with any idea of morality. Kant argues in favor of this postulate in the first part of his work: "Nowhere in the world, and nowhere is it impossible to think of anything else that could be considered good without limitation except goodwill alone. Reason, wit and power of judgment and, as if any were called differently, gifts of the spirit, or the courage, determination, commitment, as the properties of temperament in some respects, no doubt, good and desirable; but they can also be extremely evil and harmful, if not good will, which is to use these gifts of nature and 
distinctive properties which therefore are called character. Similarly, it is with the gifts of happiness. Power, wealth, honor, even health and general good condition, and satisfaction with their state under the name of happiness inspire courage and thereby often, and arrogance, when there is no goodwill that would be corrected and made universally-appropriate these gifts influence on the spirit and happiness together so on the very principle of acting. Needless to say, reasonable impartial observer can never give pleasure even the kind of permanent prosperity of man, which adorns one tittle net and goodwill; Thus, goodwill is, apparently, an indispensable condition even deserve to be happy) (Kant, 1993). Thus, morality cannot be possible without good will, no matter what other talents, abilities and virtues man possesses. The goodwill - is the foundation of human nature, and it is indispensable for the moral act. Kant further analyzes the concept of reason. Reason, in his opinion, separates humans from animals in the broadest sense; however, if we consider the question more specifically, we see that the mind functions in humans in a way that reveals a fundamental difference between humans and other living beings.

Kant uses the principle that nature creates the structure of each complex organism in such a way that there is no single body that would not perform any to him alone its intended function, and did not perform to its best and most optimal possible way. Each organ has its own purpose, and it carries it better than any other organ in a living being. From the point of view of Kant, the mind - it is also an organ that is wondering what is the purpose of its existence to man. It says: "If on the merits of having a mind and will, the true purpose was to preserve its nature, its prosperity, in a word, its happiness, it ordered would be very bad, putting on his mind doing its intention. In fact, all the actions which it should do for this, and all the rules of its conduct would have been much more accurately prefigured by its instinct with which it was possible to reach this goal much more accurately than it could ever be done with the mind "(Kant, 1993).

Kant argues that the attainment of happiness, defined as our safety or well-being - is not the functioning of the mind in the human being or beings that have the will and the mind. The welfare, safety and happiness can be achieved by means of instincts with the same or even greater success, and that with the help of reason, as we see it. Consequently, Kant says that there is "another idea, and much more dignified, the purpose of our existence; for this purpose, not for happiness is the mind, and it as the supreme condition must therefore mostly prefer personal goals of man (Kant, 1993). Kant concludes that the purpose of the existence of the mind is to develop goodwill. He says: "The mind which sees its highest practical purpose in the statement of goodwill at achieving this objective is able to meet only in its own way ...) (Kant, 1993).

In the second half of XVIII century got stronger bourgeois civilization finally prepared to throw off the shell medieval-materialistic relations. To study the process of spiritual emancipation of the individual it was needed a new concept of morality. It appeared the next urgent question: can a man, a person to find the solid moral foundations, which it had found earlier in nature, in the social environment, or in religious discourse? This question cannot be answered by traditional ethical systems. Kant argued that empirical principles of morality based on "random basis," regardless of whether it is a natural pride (as in Helvetia and Mandeville), innate moral feelings (like Shaftesbury and Hutcheson) or on education and the board (as in Montaigne and Hobbes). The theological principle of morals is free from such a chance, but it is outside for the person. Empirical ethics cannot explain definitely universal morality and theological ethics - its subjective, intrapersonal rootedness. Kant creates a theoretical concept, which is very successfully combines, both of these points. He writes: "Everyone knew that people associated with his duty to the law, but had no idea that he is the subject only to its own, and, nevertheless, universal law and that it is obliged to do, but consistent with the will of its own, install, however, universal laws of nature according to the purpose" (Kant, 1965). A. A. Guseinov in the introduction to the translated edition of "Lectures on Ethics" by Kant comments: "All the old moral principles were based on heteroposition of the will, i.e., they are outside of the current will. Kant turned this idea and understand morality as a matter of law principles, the internal framework will in the face of every rational being" (Kant, 2000).

Kant's ethics is called the ethics of duty. However, the word "duty" is not connected to an external compulsion, the concept of duty in Kant's philosophy - it is a moral conviction and pure human moral motive. Through debt moral value alleges that inherent in each man as a rational and moral features. Kant was the first in the European philosophy and culture, which entered the scientific concept of morality, concentrates entirely on the individual and morals presented as the main feature of personality-forming. Also, the ethics of Kant can be associated with individual autonomy, individual freedom and duty and ethics of good will. A. A. Guseinov writes of justification in ethics of Kant: "Speaking of the Kantian justification of morality, first of all, note: these now considered merely Kantian morality as the characteristics of the idea of the moral law, an unconditional duty and good faith, without limitation, in the ethics of Kant are not final conclusions and initial position. They are a priori, given together with the mind, though - and this is especially Kant emphasizes in "Fundamentals of the metaphysics of 
morals" - "in the ordinary human mind as well as in purely speculative" (Guseinov, 2000).

In the introduction to "The basis of the Metaphysics of Morals" Kant formulated one of the most important bases of its ethical theory: "Everyone needs to accept that the law, if it is to have the power of the moral law, that is, compulsory basis, certainly contains an absolute necessity" (Kant, 1965). This statement implies that all moral laws are categorical. For example, the Ten Commandments of Moses, philanthropy and the ritual of Confucius, the belief in Allah Muhammad have not exceptions. Thanks to these laws, individuals acquire their human identity and become one Chinese, the other a Jew, a third Muslim. These moral laws given by the ideal of man, a fundamental principle of absolute hell, which is crossed, it is possible to lose a human quality. Therefore, they have no exceptions, by definition, as are the foundation design of human existence. Morality and moral laws delineate the space of human existence.

The moral law is an objective principle of will. Because it is given by the mind, it is the law of rational beings, it is also necessary to objectively and subjectively is necessary too. The reasonableness of the will, in fact, means that the will can be guided by the principles that define the mind as a practical necessity. But one thing - the will and the mind itself, and another thing - human will and reason. The human will is governed not only by the conception of the laws: it is the laws themselves, it is able to act on the debt, and the same motivations inherent; its subjective principles may be necessary, and may be, as often happens by accident. In short, it is formed not only with the mind. Therefore, the moral law in the case of the human will acts as a constraint, as the need to act against the diverse subjective empirical effects that this will feels. It takes the form of forced dictates imperative. And not just an imperative, as a special imperative, designed specifically for the moral law. If we imagine a modern goodwill, or holy will, then it also would be guided by the moral law, but for it, this law would be the only subjective principle of acting and therefore not be performed as an imperative. Imperatives - a formula of ratio objective (moral) law to imperfect human will.

In order to describe a particular moral imperative, all the imperatives of human behavior Kant divided into two great classes: one of them the precepts are hypothetically, others are flatly. Hypothetical imperatives can be called relative, conditional. They say that the act is good in some respects, for some purpose. The act is evaluated in terms of its possible consequences. Such, for example, a doctor's advice, which is good for a person who wants to, take care of his health. The categorical imperative prescribes actions that are good in themselves, objectively, without regard to the consequences, without regard to any other purpose. As an example, it refers to the requirement of fairness. Only categorical imperative may be called moral imperative. Conversely, only the imperative of morality can be categorical. Since the moral law does not contain anything but the universal conformity to acts law, and the categorical imperative cannot be nothing but a requirement for human will be guided by the law, to bring their maxims in accordance with it, and said, what made famous formula of Kant's moral "Thus, there is only one categorical imperative, namely: "Do only according to that maxim that you at the same time you can wish that it become a universal law"' (Kant, 1965). All human morality is derived from this single principle.

Limiting the maximum Law with the condition of their validity for all rational beings means that every rational being must be seen as a limiting condition max - to the absolute limit, which is strictly forbidden to cross. Sentient beings believe in the will itself as a goal. As it does each of them, then we are talking about the principle, which is the subjective and objective (universally valid) simultaneously. The practical imperative therefore must include the idea of self-worth as a human rational being, the subject of possible goodwill and can be reformulated as follows: "Act so that you are always concerned for humanity and in your person and in the person of every other as well as to the purpose and never belonged to him only as a mean" (Kant, 1965). Mankind (humanity, inner dignity, the ability to be the subject of goodwill) in the face of every person is not just a goal, is an end in itself. This goal is the last in the sense that it can never be completely transformed into a resort. It is absolute in contrast to all other human purposes with relative character. In this sense it is negative, it is involved in behavior as a constraint - "as a goal, against which you should never do" (Kant, 1965).

The base of morality (practical law) concluded in an objective rule (universal form), subjective - in goal (every rational being as an end in itself). Categorical imperative also demands unconditional clarification of the third, namely the assumption that the will of every rational being can be morally legislation. Only under this assumption volition from duty it is clean, free of extraneous interests. Hence - the third formula of the categorical imperative, which includes "the principles of the will of each man as will all its maxims establishing universal laws" (Kant, 1965). This provision Kant calls the principle of autonomy of the will.

These are the three basic formulas, three different ways to represent the same law. They are interconnected in such a way that "it itself combines two other" (Kant, 1965). How to explain the existence of different formulas 
(editorial) of categorical imperative? The more legitimate question is, in this case we are talking about one single law. Moreover, there can be no plural or many variants of the categorical imperative, as it is unconditional, has an absolute necessity. Kant himself different ways of presenting the principle of morality explains by the need for its practical application: "It is very useful to one and the same act to push through all three of these concepts and these three as far as possible, to bring it closer to contemplation" (Kant, 1965). This explanation is much more thought out and thoroughly than it might seem at first glance.

The main feature, which focuses on Kant in search of the formula of the moral law, it is the absolute necessity. He quite naturally given the methodological question: how can be absolutely necessary (unconditional) or the law of the categorical imperative, which is the same law, but only in relation to imperfect human will. This question can be formulated differently: what properties should have the imperative of faith, so that it can be considered definitive, i.e. unconditional, absolute? He must satisfy at least three requirements: a) touch form actions, not their substantive content; b) be an end in itself; c) have their origins in the will of the acting subject. His different formulations Kant shows that the categorical imperative meet these requirements. Just as bearing constructions carefully checked the cold, heat and other natural load and Kant's categorical imperative is tested for strength in terms of the basic parameters of human acts - their content, purpose and reason. It shows that on all these important criteria categorical imperative proves its absoluteness. It is very significant in terms of content, because it does not prescribe any actions, but only applies to maximum will. It is absolute in terms of objectives, because is focused on the absolute goal, the goal in itself. It is unquestionable in terms of the reasons for its reason is the will of a rational being.

The categorical imperative, therefore, indeed, is one. And it is one. Its various formulas are different ways to demonstrate this unity and uniqueness of the categorical imperative. As the only absolute law is the moral law, the only absolute will is good will. This idea is developed with meticulous thoroughness in the study of Kant's categorical imperative, as he says without any ambiguity: "That is unconditional good will, which cannot be evil, therefore, is the maxim that if it is made a universal law, never it can contradict itself. Consequently, the principle of "always acts according to that maxim of which universality as a law that you are at the same time can wish for," also is the highest law of definitely goodwill; this is the only condition under which the will can never contradict itself, and this imperative has a categorical imperative" (Kant, n. d.).

\section{Conclusion}

So, in this article we examined the ethical system of Confucius and Kant from the standpoint of comparative study. In the ethical concepts of Confucius and Kant we can see certain things in common in the understanding of the fundamental law of morality. According to Kant, the debt is something other than moral purity of motive and firmness of moral convictions. Through debt moral value alleges that inherent in each man as a rational and moral being. Confucius category "jen" is human beginning in man, which is also his duty. We cannot say who is a person at the same time don't answer on the question of what are the signs of his moral.

The principle of "respect for the moral law" is the core of both Kant and Confucian ethics, because it opens the measurement of humane behavior. Only man can express this respect, and awareness of this respect is identical to the realization of duty, has the nature of the necessary universality. Man is called to be encouraged the mind to moral behavior that is expressed in veneration of the moral law. The meaning of life is in the connection of virtue and happiness. Only such a duty, which contributes to the happiness of man and mankind, is an ethical value.

In terms of the content (historical-philosophical aspect) mediated link is found between Confucian ethics and Kantian scheme: the system of values of Confucius - Kant's ethical system; in theory, a comparative analysis of the value system of the philosophy of Confucius and the basic principles of Kantian ethics was made.

This conclusion can be fleshed out by the following provisions:

- It can be made the analogy between the categorical imperative of Kant and the concept of "humanity" ("jen") of Confucius;

- Further research from the standpoint of comparative philosophy of "moral theories" of Confucius and Kant (and wider - Confucian ethics and Kantian) will help to uncover the deeper layers of interaction and mutual understanding between Eastern and Western philosophical traditions.

\section{References}

Betzler, M. (2008). Kant's ethics of virtue (p. 296). http://dx.doi.org/10.1515/9783110209655

Chukhina, L. A. (1989). The problem of man in the philosophy of Immanuel Kant's ethics. Kant and modernity. Collection of articles. Riga: Avots. 
de Gruiter.Hegel, G. W. F. W. (1932). Lectures on the history of philosophy (p. 111). Moscow.

Froese, K. (2013). Ethics Unbound. Chinese and Western perspectives on Morality. The Chinese University Press.

Fung, Y. L. (1973). A history of Chinese philosophy (Vol. I). The period of the philosophers (from the beginnings to circa 100 B.C.). Princeton University Press.

Grigorieva, T. P. (1994). The idea of the fate of the East. The concept of fate in the context of different cultures (pp. 98-109). Moscow: Nauka.

Guseinov, A. A. (2000). Moral and Mind. Lectures on Ethics (p. 431). Moscow: Republic.

Jaspers, K. (1991). Meaning and purpose of history (p. 528). Moscow: Politizdat.

Kant, I. (1965). Works in six volumes, 4(I), 544, 270, 274, 278-279, 280.

Kant, I. (1988). In L. W. Beck (Ed.), Idea for a Universal History from a Cosmopolitan Point of view in Kant Selections. New York: Macmillan Publishing Company.

Kant, I. (1993). Grounding for the Metaphysics of Morals (p. 7, 3rd ed.). Trans, James W. Ellington. Indianapolis: Hackett Publishing Company.

Kant, I. (n. d.). Fundamentals of the metaphysics of morals. Retrieved fromhttp://www.deir.org/libr/?go=book $\& \mathrm{id}=428 \& \mathrm{p}=23$

Kobzev, A. I. (1988). Features philosophical and scientific methodology in traditional China. In C. Statey (Ed.), Ethics and ritual in traditional China (pp. 17-55). Moscow: Home Edition Oriental Literature of the Islands "Science".

Perelomov, L. S. (1993). Confucius life, teaching, destiny (p. 440). Moscow: Nauka.

Roetz, H. (1992). The Chinese Ethics of the Axial Period: A reconstruction from the point of Durchbruchszu post conventional Denken (p. 480). Frankfurt-on-Mine.

Rousseau, J. J. (1998). The Social Contract. Treatises (p. 416). Moscow: CANON-press Kuchkovo pole.

Rubinstein, S. L. (1997). The man and the world (p. 191). Moscow: Nauka.

Sanya, M. Z., \& Chi, Z. Z. Y. X. (1968). Essence of the heart (the spirit) and essence (human) nature, V, 1-3. Taipei.

Solovyov, E. Y. (1978). The problem of the philosophy of history in the later works of Kant. Problems of theoretical heritage of Immanuel Kant, 3, 73.

Special: Institute of Philosophy and Law. Russian Academy of Sciences Research Institute (UMC) Federal NSPU. (2007). Understanding art in Confucian pedagogy as a way to self-improvement human (p. 315). Philosophy of Education. Moscow.

Tu, W. M. (1979). Humanity and Self-Cultivation: Essays in Confucian Thought (p. 8). Berkeley.

\section{Copyrights}

Copyright for this article is retained by the author(s), with first publication rights granted to the journal.

This is an open-access article distributed under the terms and conditions of the Creative Commons Attribution license (http://creativecommons.org/licenses/by/3.0/). 